Original Article

\title{
The effects of short foot exercises and arch support insoles on improvement in the medial longitudinal arch and dynamic balance of flexible flatfoot patients
}

\author{
Eun-Kyung Kim, PT, $\mathrm{PhD}^{1)}$, Jin Seop Kim, PT, $\mathrm{PhD}^{2)^{*}}$ \\ 1) Department of Physical Therapy, Seonam University, Republic of Korea \\ 2) Department of Physical Therapy, Sunmoon University: 70 Sunmoonro, 221 Beongil, \\ Tangjeong-Myeon, Asansi, Chungnam 336-708, Republic of Korea
}

\begin{abstract}
Purpose] The purpose of the present study is to apply short foot exercises and arch support insoles in order to improve the medial longitudinal arch of flatfoot and compare the results to identify the effects of the foregoing exercises on the dynamic balance of the feet and the lower limbs. [Subjects and Methods] Fourteen university students with flexible flatfoot were selected by conducting navicular drop tests and randomly assigned to a short foot exercise group of seven subjects and an arch support insoles group of seven subjects. The intervention in the experiment was implemented for 30 minutes per time, three times per week for five weeks in total. [Results] In inter-group comparison conducted through navicular drop tests and Y-balance tests, the short foot exercise group showed significant differences. Among intra-group comparisons, in navicular drop tests, the short foot exercise group showed significant decreases. In Y-balance tests, both the short foot exercise group and the arch support insoles group showed significant increases. [Conclusion] In the present study, it could be seen that to improve flatfoot, applying short foot exercises was more effective than applying arch support insoles in terms of medial longitudinal arch improvement and dynamic balance ability.

Key words: Short foot exercise, Arch support insoles, Flatfoot
\end{abstract}

(This article was submitted Jun. 1, 2016, and was accepted Jul. 21, 2016)

\section{INTRODUCTION}

Although the feet occupy only $5 \%$ of the areas of the human body, they control postures through afferent information obtained through the sense of the soles, provide stability for maintenance of balance, and absorb impacts ${ }^{1)}$.

The deformation into flatfoot is induced when the medial longitudinal arch (MLA) has descended because the arch had been excessively relaxed to the extent that the arch cannot be maintained and causes the feet to be excessively pronated compared to normal feet so that heel eversion appears and the weight load is shifted inward to compress the MLA ${ }^{2,3)}$. When the MLA has descended or has been completely lost leading to structural or functional deformation, the ability to absorb impacts will decrease and the sense of balance will be lost so that stability decreases during walking or running leading to walking difficulties and endurance decreases ${ }^{4,5)}$.

Foot wedges are clinically applied for correction of diverse foot diseases and for maintenance of balance ${ }^{6}$, and customized insoles are used for correction of pronated feet ${ }^{7)}$. Insoles widen the contact surface of the sole to improve stability during weight bearing, reduce turning actions when the foot has been pronated or supinated, and can be applied to the medial longitudinal arch of the foot to increase the sensory inputs of the sole ${ }^{8}$. Study results have been reported indicating that the

*Corresponding author. Jin Seop Kim (E-mail: skylove3373@sunmoon.ac.kr)

(C2016 The Society of Physical Therapy Science. Published by IPEC Inc.

This is an open-access article distributed under the terms of the Creative Commons Attribution Non-Commercial No Derivatives (by-nc-nd) License $<$ http://creativecommons.org/licenses/by-nc-nd/4.0/>. 
Table 1. General characteristics of the subjects

\begin{tabular}{lcc}
\hline & SFE group $(\mathrm{n}=7)$ & ASI group $(\mathrm{n}=7)$ \\
\hline Gender (male/female) & $6 / 1$ & $4 / 3$ \\
Age (years) & $24.0 \pm 1.9^{\mathrm{a}}$ & $24.1 \pm 1.5$ \\
Height $(\mathrm{cm})$ & $172.2 \pm 6.9$ & $167.0 \pm 6.7$ \\
Weight $(\mathrm{kg})$ & $68.2 \pm 12.9$ & $63.3 \pm 17.6$ \\
\hline
\end{tabular}

${ }^{\mathrm{a}}$ Mean $\pm \mathrm{SD}$

conservative intervention methods of foot orthotics using support for the arch of the foot improve malformations of the foot, are effective for leg alignment and pain control, and improve gaits to become normal ${ }^{7}$.

The previous reported that sole stimulation could improve the motor sensation and postural movements to maintain proper postures ${ }^{9}$. Sensory-motor training applies the proprioceptive feedback of the body to activate the abductor pollicis muscle and the flexor hallucis brevis muscle, which are the intrinsic muscles of the feet important for maintenance of the MLA, to help the formation of the arch and the maintenance of the balance of the body ${ }^{10)}$. In addition, sensory-motor training delivers proprioceptive sensory signals to the sensory cortex area of the brain and affects even the motor area to improve the asymmetric muscle tone of the sole and draw appropriate new movements thereby improving the motor sensation and postural disturbance to help maintaining the balance and stability of the body ${ }^{9}{ }^{11)}$. Fiolkowski et al. reported that sensory stimulation training was helpful for flatfoot patients to form and support the $\operatorname{arch}^{12)}$.

Among exercise methods to improve flatfoot, toe bending exercises or towel-curl exercises mainly mobilize the extrinsic muscles of the foot such as the flexor digitorum longus muscle ${ }^{13}$. However, short foot exercises (SFE) are sensory-motor training that activates the intrinsic muscles of the foot and actively forms the longitudinal arch and the horizontal $\operatorname{arch}^{14,15)}$ Although studies utilizing foot orthotics such as therapeutic footwear, wedges, and insoles to improve the MLA of flatfoot have been mainly conducted, studies for improvement of flatfoot that compared foot orthotics with sensory-motor training such as SFE are insufficient.

Therefore, the present study is intended to improve the MLA of flatfoot and investigate the effects of the improvement on the dynamic balance of the feet and the lower limbs to identify effective application methods.

\section{SUBJECTS AND METHODS}

The subjects of the present study were 14 university students (males 10, females 4) aged 21 to 26 years sampled from among students in the health college of S University in Asan-si, Chungcheongnam-do and the experiments were conducted from October to December 2015. Before the experiments, the overall details of the purpose and procedure of the present study were explained to all subjects pursuant to the ethical standard of the Declaration of Helsinki and the subject voluntarily agreed to participate in the experiments. The subjects that participated in the experiments were randomly assigned to an SFE group of seven subjects and an arch support insoles (ASI) group of seven subjects.

The selection criteria for participating subjects regarded the foot used to kick balls as the dominant foot to select subjects with flatfoot. Navicular drop tests (NDT) were conducted to select those that had flexible flatfoot with a $10 \mathrm{~cm}$ or larger difference in the navicular tuberosity heights and those that were performing lower limb exercises separately, or had any foot hypoesthesia, fracture, dislocation, skin disease, or vascular disease were excluded. The dominant foot of all subjects was the right foot. The subjects' general characteristics are as shown in Table 1 and the SFE group's mean age, height, and weight were $24.0 \pm 1.9$ years, $172.2 \pm 6.9 \mathrm{~cm}$, and $68.2 \pm 12.9 \mathrm{~kg}$ respectively. The ASI group's mean age, height, and weight were $24.1 \pm 1.5$ years, $167.0 \pm 6.7 \mathrm{~cm}$, and $63.3 \pm 17.6 \mathrm{~kg}$ respectively.

SFE was implemented as sensory-motor training for improvement in the flatfoot of the experimental group. Before the intervention, the researcher demonstrated the short foot exercises while giving verbal instructions. Thereafter, each subject was instructed to sit on a height-adjustable chair and bend the hip joint, knee joints, and ankle joints to $90^{\circ}$ and a towel was placed below the feet. Thereafter, the subject was instructed to pull the head of the first metatarsal bone toward the heel without bending the toes and maintain the state for $20 \mathrm{sec}$ to form the MLA. During the exercise, to prevent the forefoot and the heel from being lifted off the ground and smoothly induce the flexion of the head of the metatarsal bone, the measurer gently held the instep and the heel ${ }^{15)}$. The posture was maintained for $10 \mathrm{sec}$ followed by $5 \mathrm{sec}$ and this process was implemented for 30 minutes per time, three times per week for a total of five weeks.

As a method for improvement in the flatfoot of the control group, insoles were applied as medial arch support structures. To make the insoles, the foot shape of each subject was sketched on $3.2 \mathrm{~mm}$ thick Aquaplast- ${ }^{\circledR}$ (Sammons Preston Rolyan, USA), which is a thermoplastic material. Thereafter, the Aquaplast- $\mathrm{T}^{\circledR}$ was cut out using scissors, wetted with $100{ }^{\circ} \mathrm{C}$ water, and attached to the sole of the subject to copy the foot and the height of the arch. Thereafter, the MLA was made with a shore value of $20^{\circ}$ and a height of at least $15 \mathrm{~mm}^{16}$ ). The insoles made as such were given to the subjects and the subjects were instructed to put the insoles into their running shoes and walk on flatlands for 30 minutes per time, three times per week for 
Table 2. Comparison of changes in navicular drop height and dynamic balance between the groups

\begin{tabular}{lcccc}
\hline \multirow{2}{*}{ Variable } & \multicolumn{2}{c}{ SFE group } & \multicolumn{2}{c}{ ASI group } \\
\cline { 2 - 5 } & Pre-test & Post-test & Pre-test & Post-test \\
\hline Navicular drop test $(\mathrm{mm})$ & $11.4 \pm 1.6^{\mathrm{a}}$ & $7.7 \pm 1.1^{* \dagger}$ & $12.2 \pm 1.8$ & $10.5 \pm 1.7$ \\
Y balance test $(\%)$ & $74.3 \pm 8.3$ & $82.4 \pm 7.4 \dagger$ & $72.4 \pm 7.1$ & $74.2 \pm 7.2 \dagger$ \\
\hline
\end{tabular}

${ }^{\mathrm{a}} \mathrm{Mean} \pm \mathrm{SD}$

*Significant differences between the SFE and the ASI groups $(\mathrm{p}<0.05)$

$†$ Significant differences between pre- and post-tests $(\mathrm{p}<0.05)$

a total of five weeks.

NDTs were conducted to measure changes in the height of the MLA. In the NDT, each subject was instructed to sit on a chair with the knee joint bent to $90^{\circ}$ and align the second toe and the knee so that the subtalar joint was placed on the neutral position and under a non-weight bearing condition, the distance from the ground to the navicular tuberosity was measured and marked. Thereafter, the distance from the ground to the navicular tuberosity was measured in a standing position with the feet place at shoulder width and weight bearing by the two feet. Using a plastic ruler and a $3 \times 5$ index card, the difference in the height of the navicular tuberosity between the non-weight bearing(sitting position) position and the weight bearing (standing position) position was measured three times repeatedly and the average value was used.

Y-balance tests (YBT) (Move2Perform, Evansville, IN, USA) were conducted to measure the dynamic balance ability of the leg. The Y-balance test (YBT) kit consists of three directional (anterior, posteromedial, posterolateral) PVC pipe graduated rulers. Each subject stood on the platform located on the center on the YBT kit with the bare foot of the leg to be measured and pushed the reach indicator placed on the PVC pipe graduated ruler with the other leg and the maximum reached distance was measured. The PVC pipe graduated ruler has $0.5 \mathrm{~cm}$ grades and thus the distance was recorded in $0.5 \mathrm{~cm}$ units. During the measurement, considering the reaching ability depending on leg lengths, the leg length of each subject was measured and normalized and to minimize learning effects on measurement, reaching was practiced two times in each direction before measurement. The measurement was performed in the same order of directions and each distance was measured two times and the average value was calculated. Normalized composite reach distance was computed for each leg as the sum of the maximum reach distances (in centimeter) in the 3 directions, divided by 3 times the limb length, and then multiplied by $100^{17)}$.

The measured data were statistically processed using PASW Statistics ver. 18.0. The general characteristics of the subjects were presented as means and standard deviations using descriptive statistics (Table 1). Independent t-tests were conducted to compare the amounts of changes between the two groups and Paired t-tests were used to measure differences before and after experiment in each group. The statistical significance level was set to $\alpha=0.05$ for all data.

\section{RESULTS}

Changes in the NDT and YBT of the SFE group and the ASI group are as shown in Table 2. According to the results on inter-group NDT comparisons, the values of the SFE group significantly decreased after intervention compared to the ASI group and according to the results of YBT comparisons, the values of the SFE group significantly decreased after intervention compared to the ASI group ( $\mathrm{p}<0.05$ ). In intra-group NDT comparison between before and after intervention, whereas the SFE group showed significant decreases, the ASI group showed no significant difference and in intra-group YBT comparison, both the SFE group and the ASI group showed significant increases $(\mathrm{p}<0.05)$.

\section{DISCUSSION}

In the case of flatfoot, as the pronated state of the heel is maintained, the talus bone is moved to the inside of the sole leading to the disappearance of the medial longitudinal arch so that the ability to accommodate and distribute the weight is reduced compared to normal persons ${ }^{3}$. Structural deformation of the feet leads to lesions in the ankle joint and the feet and problems in lower limb joints, results in early fatigue and pain due to the excessive compensating actions of the intrinsic muscles and the extrinsic muscles, and causes problems in the stability and balance of the feet during gaits ${ }^{18)}$. To improve these flatfoot conditions, methods that correct the MLA using foot orthotics or therapeutic footwear are universally used ${ }^{15)}$. Other intervention methods include SFE for strengthening the intrinsic muscles and extrinsic muscles of the foot through sensory-motor training. Synder et al. presented SFE as the most positive method among methods of correcting the eversion of the subtalar articulation ${ }^{19}$ ). The SFE induces the head of the metatarsal bone to approach the heel without bending the toes in a state where the weight is borne ${ }^{15)}$.

In the present study, attempts were made to improve flatfoot conditions through changes in the height of the MLA by applying SFE for six weeks. According to the results of measurement using NDT, the descending distance of the navicular bone decreased from $11.4 \pm 1.6 \mathrm{~mm}$ before intervention to $7.7 \pm 1.1 \mathrm{~mm}$ after intervention indicating that SFE was effective. 
However, in the ASI group, changes in the medial longitudinal arch were not significant. In a study conducted by Allen \& Glasoe, the mean descending distance of the MLA was shown to be $7.3 \pm 3.8 \mathrm{~mm}^{20}$ ). This indicates that a flexible flatfoot can form ab arch close to that of normal feet through exercise through SFE for six weeks. Lynn et al. reported that towel-curl exercises implemented for four weeks as foot intrinsic muscle strengthening exercises were effective ${ }^{21)}$ and Jung et al. reported that when toe curl exercises and arch formation exercises were applied, the rear foot angle significantly decreased while foot intrinsic muscle strength was improved ${ }^{15)}$.

Telfer et al. reported that changes in the structure of the arch of the sole affected balance ability and gait ability ${ }^{7)}$. In the present study, when dynamic balance was measured using YBT, both the SFE group and the ASI group showed significant improvement between before and after intervention within each group. This is considered attributable to the fact that short foot exercises improved the functions and activity of the abductor pollicis muscle that plays the role of bearing the weight and pushing the body forward during push off in gaits and the flexor hallucis brevis muscle that maintains the MLA during the terminal stance in gaits to maintain foot stability ${ }^{10}$. The reason why dynamic balance ability was significantly improved in the group applied with arch support insoles is considered to be the fact that the support for the medial longitudinal arch reduced maximum load reactions to improve leg stability thereby brining about dynamic biomechanical effects ${ }^{11)}$.

In the present study, short foot exercises and arch support insoles were applied to improve flatfoot conditions and it could be seen that as the medial longitudinal arch was improved, dynamic balance ability was improved. In addition, it could be seen that sensory-motor training such as short foot exercises was more effective than conservative treatment methods such as arch support insoles. In addition, it could be seen that the intervention period of six weeks was not sufficient to improve the medial longitudinal arch using arch support insoles. Detailed comparison studies combining sensory-motor training of the foot and arch support insoles with more sufficient intervention periods are necessary.

\section{REFERENCES}

1) Hillstrom HJ, Song J, Kraszewski AP, et al.: Foot type biomechanics part 1: structure and function of the asymptomatic foot. Gait Posture, 2013, 37: 445-451. [Medline] [CrossRef]

2) Flemister AS, Neville CG, Houck J: The relationship between ankle, hindfoot, and forefoot position and posterior tibial muscle excursion. Foot Ankle Int, 2007, 28: 448-455. [Medline] [CrossRef]

3) Korpelainen R, Orava S, Karpakka J, et al.: Risk factors for recurrent stress fractures in athletes. Am J Sports Med, 2001, 29: 304-310. [Medline]

4) Abouaesha F, van Schie CH, Griffths GD, et al.: Plantar tissue thickness is related to peak plantar pressure in the high-risk diabetic foot. Diabetes Care, 2001, 24: 1270-1274. [Medline] [CrossRef]

5) Citaker S, Gunduz AG, Guclu MB, et al.: Relationship between foot sensation and standing balance in patients with multiple sclerosis. Gait Posture, 2011, 34: 275-278. [Medline] [CrossRef]

6) Albert S, Rinoie C: Effect of custom orthotics on plantar pressure distribution in the pronated diabetic foot. J Foot Ankle Surg, 1994, 33: 598-604. [Medline]

7) Telfer S, Abbott M, Steultjens M, et al.: Dose-response effects of customised foot orthoses on lower limb muscle activity and plantar pressures in pronated foot type. Gait Posture, 2013, 38: 443-449. [Medline] [CrossRef]

8) Coughlin MJ: Roger A. Mann Award. Juvenile hallux valgus: etiology and treatment. Foot Ankle Int, 1995, 16: 682-697. [Medline] [CrossRef]

9) Maki BE, Perry SD, Norrie RG, et al.: Effect of facilitation of sensation from plantar foot-surface boundaries on postural stabilization in young and older adults. J Gerontol A Biol Sci Med Sci, 1999, 54: M281-M287. [Medline] [CrossRef]

10) Hrysomallis C: Relationship between balance ability, training and sports injury risk. Sports Med, 2007, 37: 547-556. [Medline] [CrossRef]

11) Razeghi M, Batt ME: Foot type classification: a critical review of current methods. Gait Posture, 2002, 15: 282-291. [Medline] [CrossRef]

12) Fiolkowski P, Brunt D, Bishop M, et al.: Intrinsic pedal musculature support of the medial longitudinal arch: an electromyography study. J Foot Ankle Surg, 2003, 42: 327-333. [Medline] [CrossRef]

13) Saeki J, Tojima M, Torii S: Clarification of functional differences between the hallux and lesser toes during the single leg stance: immediate effects of conditioning contraction of the toe plantar flexion muscles. J Phys Ther Sci, 2015, 27: 2701-2704. [Medline] [CrossRef]

14) Janda V, Vavrova M: Sensory motor stimulation. In: Rehabilitation of the Spine. Liebenson C (ed.), Baltimore: Williams \& Wilkins, 1996, pp 319-328.

15) Jung DY, Kim MH, Koh EK, et al.: A comparison in the muscle activity of the abductor hallucis and the medial longitudinal arch angle during toe curl and short foot exercises. Phys Ther Sport, 2011, 12: 30-35. [Medline] [CrossRef]

16) Jones RK, Nester CJ, Richards JD, et al.: A comparison of the biomechanical effects of valgus knee braces and lateral wedged insoles in patients with knee osteoarthritis. Gait Posture, 2013, 37: 368-372. [Medline] [CrossRef]

17) Plisky PJ, Gorman PP, Butler RJ, et al.: The reliability of an instrumented device for measuring components of the star excursion balance test. N Am J Sports Phys Ther, 2009, 4: 92-99. [Medline]

18) Neumann DA: Kinesiology of the musculoskeletal system: foundations for physical rehabilitation. St Louis: Mosby, 2009.

19) Snyder KR, Earl JE, O'Connor KM, et al.: Resistance training is accompanied by increases in hip strength and changes in lower extremity biomechanics during running. Clin Biomech (Bristol, Avon), 2009, 24: 26-34. [Medline] [CrossRef]

20) Allen MK, Glasoe WM: Metrecom measurement of navicular drop in subjects with anterior cruciate ligament injury. J Athl Train, 2000, 35: 403-406. [Medline]

21) Lynn SK, Padilla RA, Tsang KK: Differences in static- and dynamic-balance task performance after 4 weeks of intrinsic-foot-muscle training: the short-foot exercise versus the towel-curl exercise. J Sport Rehabil, 2012, 21: 327-333. [Medline] [CrossRef] 